\title{
INTEGRATION OF INSAR TECHNIQUE, GOOGLE EARTH IMAGES AND EXTENSIVE FIELD SURVEY FOR LANDSLIDE INVENTORY IN A PART OF CAMERON HIGHLANDS, PAHANG, MALAYSIA
}

\author{
MoHAMmadi, A. ${ }^{1}-$ SHAHABI, H..$^{2 *}$ - Bin AHMAD, B. ${ }^{1}$ \\ ${ }^{1}$ Faculty of Built Environment and Surveying, Universiti Teknologi Malaysia (UTM) \\ 81310 Johor Bahru, Malaysia \\ (e-mails: ayubmohammadi1990@gmail.com,baharinahmad60@gmail.com) \\ ${ }^{2}$ Department of Geomorphology, Faculty of Natural Resources, University of Kurdistan \\ Sanandaj, Iran \\ *Corresponding author \\ e-mail: h.shahabi@uok.ac.ir; phone: +98-918-665-8739 \\ (Received $30^{\text {th }}$ Aug 2018; accepted $7^{\text {th }}$ Nov 2018)
}

\begin{abstract}
Landslide is among hazardous kind of disasters, which claiming many of lives and billions of dollars of damages in property every year. Detecting the spatial distribution of landslides is highly important in decision making. Interferometry synthetic aperture RADAR (InSAR) is a technique have been employed in many studies, including land surface deformation. The Google Earth (GE) with images in high spatial resolution provide a potential for regional landslide mapping, especially in vegetated areas, where landslides creates bare lands. This study aims to detect landslide locations using integration of InSAR technique, Google Earth images and extensive field survey in a part of Cameron Highlands, Pahang, Malaysia. A pair of synthetic aperture RADAR (SAR) images were acquired from scihub.copernicus.eu website. In order to extract surface deformation, either imageries were preprocessed and processed through sentinel application platform (SNAP) software. A total number of 152 landslide locations were extracted from phase, coherence and unwrapped bands with the help of the Google Earth images, where they were overlaid on the Google Earth and by zooming in deformed surfaces the landslide locations were identified, extracted and converted into layer format using Geographical Information System (GIS). Geographical Positioning System (GPS) was utilized for validation purposes.
\end{abstract}

Keywords: remote sensing, geographical positioning system, landslide detection, Cameron Highlands, Malaysia

\section{Introduction}

Landslide is one of major type of geo-hazards claiming thousands of lives and causing billions of dollars of damages in property every year (Shahabi et al., 2013). Landslide is triggered by some extreme events, including earthquakes, precipitations, volcanic eruptions, anthropogenic-based actions and etc. However, identifying the spatial distribution of landslides is crucial for managing and planning in situ investigations (Yang and Chen, 2010; Shahabi and Hashim, 2015). Interferometry synthetic aperture RADAR (InSAR) is a technique, which can be employed in numerous fields, including tectonic (Massonnet et al., 1993), volcanic (Stevens and Wadge, 2004; Wright et al., 2006), subsidence (Tomás et al., 2005, 2014; Herrera et al., 2007), landslides (Sun et al., 2015; Tomás et al., 2016), ice flow (Goldstein et al., 1993), digital elevation model (DEM) generation (Pauciullo et al., 2015). The Google Earth (GE) images have been widely developed and used in many sectors. With free 
images in high spatial resolution the Google Earth images provide high potential for regional landslide mapping (Van Den Eeckhaut et al., 2012; Pham et al., 2016), especially in vegetated areas, where the landslides create bare lands, therefore can be easily detected through visual interpretation.

Due to the weak soil structure and heavy rainfall, Cameron Highlands is highly prone to landslide and has faced many landslides to date, which led to significant damages in properties (Jebur et al., 2015). Even for areas of a few $\mathrm{km}^{2}$, RADAR imageries are remarkably expensive and acquiring such data are quite challenging. The study area is covered by cloud almost a whole year and on the other side is highly vegetated. However, the only alternative for landslide detection in such areas is RADAR remote sensing, which can penetrate through cloud coverage, vegetation foliage and work day and night (Chitroub et al., 2002; Lillesand et al., 2014).

RADAR imageries are costly, but SENTINEL-1 satellite products are among the most important and applicable source of RADAR data, which can be obtained online. SAR image is independent of solar energy and information can be taken day and night (Chitroub et al., 2002). Interferometry synthetic aperture RADAR (InSAR) technique is a RADAR technique used in many areas, including land surface deformation. Satellite synthetic aperture RADAR images are taken in separate days, therefore changes that have occurred between RADAR images are then recorded. This technique can monitors millimetre to centimetre scale deformation resulting from landslides, earthquakes, volcanoes and human induced factors (Van Baelen and Richmond, 1991). However, with millions of users, GE imagery has been recognized as one of the important sources of scientific data (Potere, 2008).

Many studies have been focused on landslide inventory by using different models, methods and imageries worldwide, including aerial photo interpretation (Wieczorek, 1984; Brardinoni et al., 2003; Fiorucci et al., 2011; Guzzetti et al., 2012; Strozzi et al., 2013; Li et al., 2016; Garcia-Urquia and Yamagishi, 2017; Chen et al., 2018; Marchesini et al., 2018), satellite imageries (Singhroy et al., 1998; Nichol and Wong, 2005; Nichol et al., 2006; Marcelino et al., 2009; Fiorucci et al., 2011; Ardizzone et al., 2013; Shahabi et al., 2014, 2015; Pradhan et al., 2016; Wang et al., 2018), the Google Earth images (Costanzo et al., 2012; Van Den Eeckhaut et al., 2012; Li et al., 2015; Conoscenti et al., 2016; Maki Mateso et al., 2016; Pham et al., 2016, 2017; Broeckx et al., 2018; Yamagishi and Moncada, 2018), interferometry synthetic aperture RADAR (InSAR) technique (Singh et al., 2005; Greif and Vlcko, 2012; Motagh et al., 2013; Bellotti et al., 2014; Tang et al., 2015; Tomás et al., 2016; Bayer et al., 2018; Tien Bui et al., 2018), differential interferometry synthetic aperture RADAR (DInSAR) technique (Cascini et al., 2010; Herrera et al., 2013; García-Davalillo et al., 2014; Ferlisi et al., 2015; Infante et al., 2016; Calvello et al., 2017; Nobile et al., 2018).

However, convergence of above mentioned methods was the strong point of the current study compared with other studies, where only one or two methods used for landslide inventory (Cascini et al., 2010; Bellotti et al., 2014; Ferlisi et al., 2015; Bayer et al., 2018). On the other hand, for a better result the Google Earth imagery as well as extensive field checks were highly needed in this study, which concern with the hilly situation of Camron Highlands, another issue was the field survey. Therefore, integration of InSAR technique, the Google Earth image and extensive field survey as well as employing SENTINEL-1 satellite imagery as the only available RADAR imagery online for free, are the significances of the current study. Finally, the main objective of this work was to detect landslide locations for a part of Cameron 
Highlands, Pahang, Malaysia by using integration of interferometry synthetic aperture RADAR (InSAR) technique, the Google Earth images and extensive field investigation.

\section{Materials and methods}

\section{Description of the study area}

A part of Cameron Highlands, Pahang, Malaysia was selected for the application of landslide detection, which is located in the south western part of Cameron Highlands with an area of $81.249 \mathrm{~km}^{2}$. The study area (Fig. 1) is experiencing rapid development of land clearing for housing, hotels and apartments, which lead to erosion and landslides (Pradhan et al., 2010). Cameron Highlands is located in the Main Range of Malaysia geological units (Makoundi et al., 2014). In the study area, there are two kind of formations, including acid intrusive and schist, phyllite, slate, limestone with minor intercalation of sandstone. The lowest and the highest area in the region is 953 and $1944 \mathrm{~m}$ above the sea level, respectively. Refer to Tropical Rainfall Measuring Mission (TRMM) data, the average rainfall in the study area for the year 2017 fluctuates between $3800 \mathrm{~mm}$ to $4200 \mathrm{~mm}$ annually. There are two wet seasons in Malaysia from September to December and also from February to May (Pradhan et al., 2010; Rasul et al., 2017). However, the rainfall in Cameron Highlands express itself between March and May and from November to December (Pradhan et al., 2010). During these specific times, rivers in Cameron Highlands overflow and flooding the surrounding areas, therefore landslides may occur along the river banks.
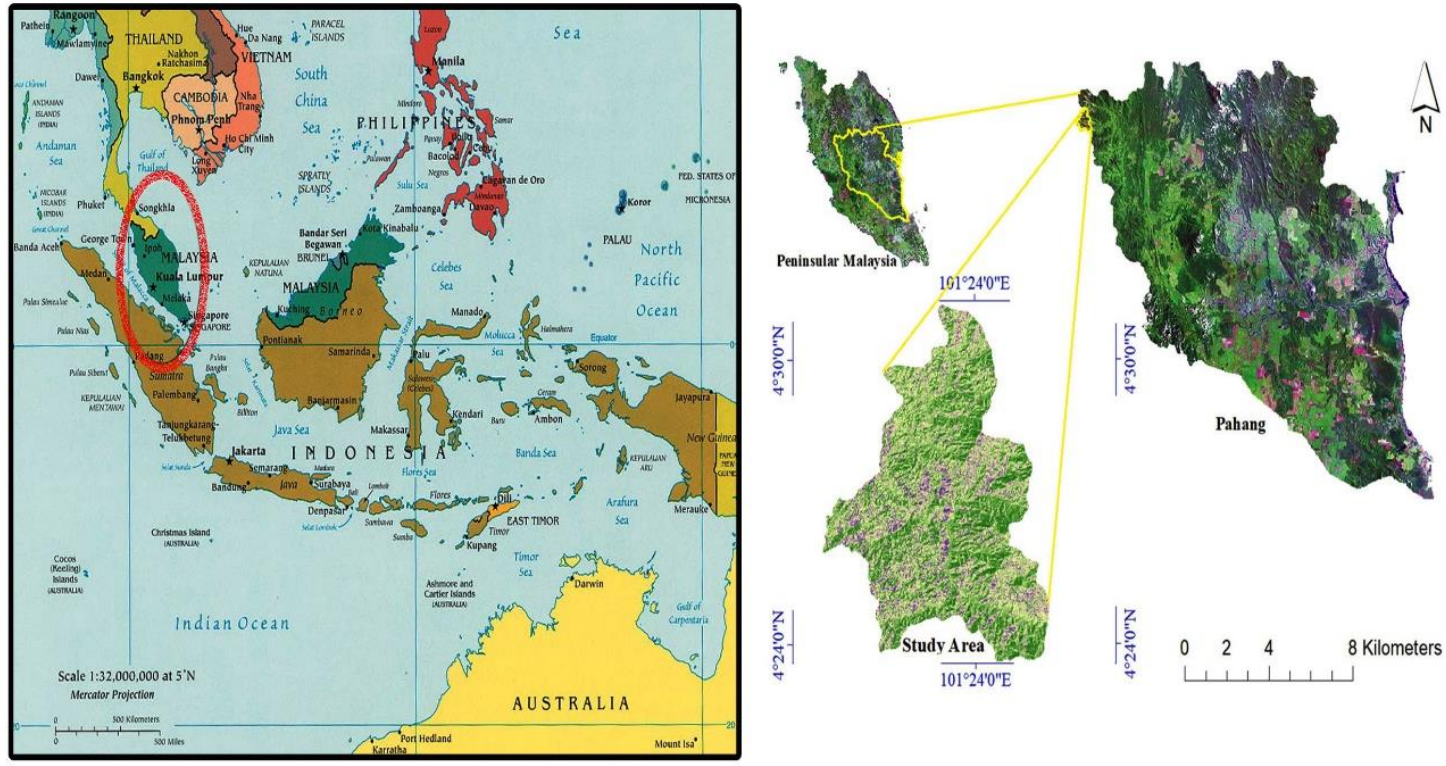

Figure 1. Shows geographical location of the study area in Asia and Malaysia

\section{Data base and data collection}

Images that are taken in separate days and positions are able to record occurred changes between two imageries. Two or more satellite imageries of the same area and the same position, which used for topographic studies at slightly different positions are generally applied to create map of surface deformation using interferometry synthetic 
aperture RADAR (InSAR) technique (Massonnet and Feigl, 1998; Bürgmann et al., 2000; Hanssen, 2001). For this matter we acquired two SENTINEL-1 images of a different dates and different topographic positions for generating interferogram in this study.

SENTINEL-1 is the first Copernicus Programme, which conducted by the European Space Agency (ESA). This product consists of the two satellite platforms of SENTINEL-1A and SENTINEL-1B. SENTINEL-1 has four sensor modes of interferometric wide swath (IW), strip map (SM), wave (WV), and extra wide swath (EW), however, three product types of SENTINEL-1 are namely, ground range detected (GRD), single look complex (SLC), and ocean (OCN) (Potin et al., 2012).

It is in C-band with $5.7 \mathrm{~cm}$ wavelength, which able to get data day and night in all weather conditions, however, the short wavelength of C-band SAR sensors is an obstacle in highly vegetated areas, because cannot penetrates through thick trunk and branches of trees (Geudtner et al., 2014). In this study a pair of SENTINEL-1 image were obtained from scihub.copernicus.eu website for free. Table 1 and Figure 2 illustrate the technical characteristics of SENTINEL-1 data and geographical position of the study area on satellite imagery, respectively.

Table 1. Technical attributes of SENTINEL-1 data used in the study area

\begin{tabular}{c|c|c|c|c}
\hline Platform & Sensor mode & Product type & Path & Date \\
\hline \multirow{2}{*}{ S1A } & Interferometry Wide & Single Look & \multirow{2}{*}{ Ascending } & $20 / 02 / 2017$ \\
& swath (IW) & Complex (SLC) & & $04 / 03 / 2016$ \\
\hline
\end{tabular}
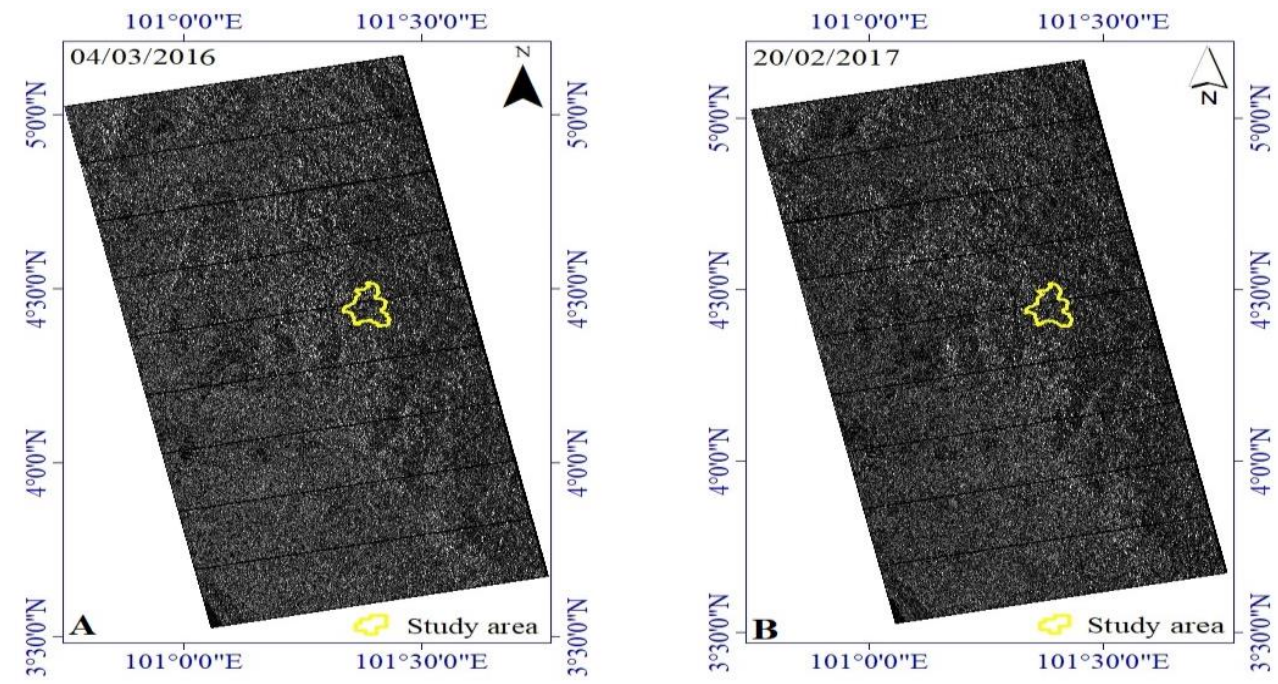

Figure 2. SENTI NEL-1 data used in the study area

\section{Data pre-processing and processing}

The comparison of the phase values in two different radar images, known as InSAR technique (Navarro-Sanchez et al., 2010; Jebur et al., 2015). A pair of synthetic aperture RADAR (SAR) images are required to generate an interferogram. However, prior to InSAR processing the raw data must be pre-processed. In this study, in order to pre- 
process and process the imageries, sentinel application platform (SNAP) software was employed. Figure 3 clearly shows the step by step methodology of the current study.

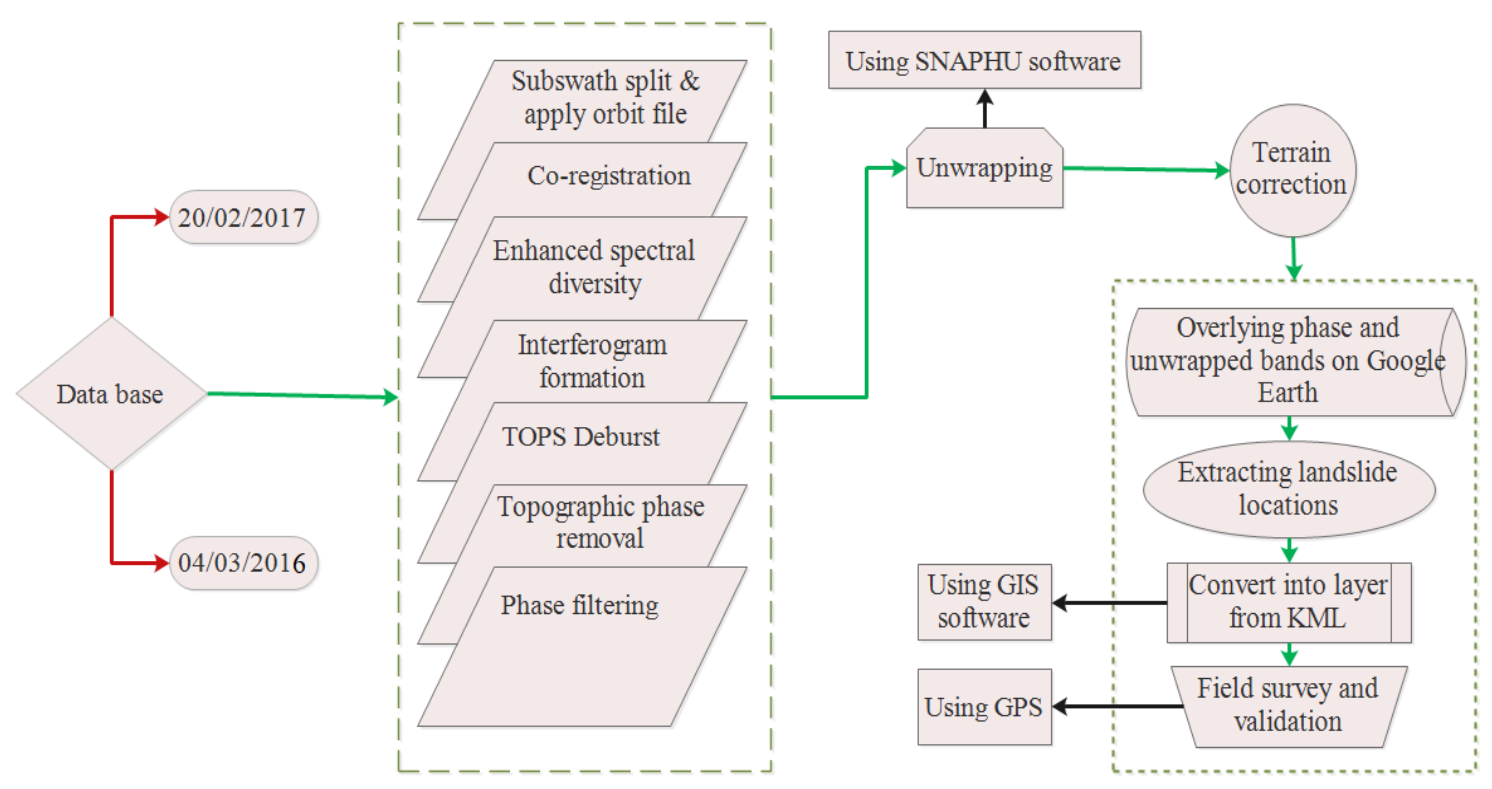

Figure 3. Methodology of the study area

\section{TOPS split and apply orbit file}

SENTINEL-1 products have three sub-swaths, which must be split and based on the study the appropriate one should be selected (Luis, 2015). After sub-swaths step, the orbit file has to be updated. 3 sub-swaths of IW1, IW2 and IW3 can be seen in SENTINEL-1 imageries, which each of them belongs to an adjacent acquisition (Fig. 4).

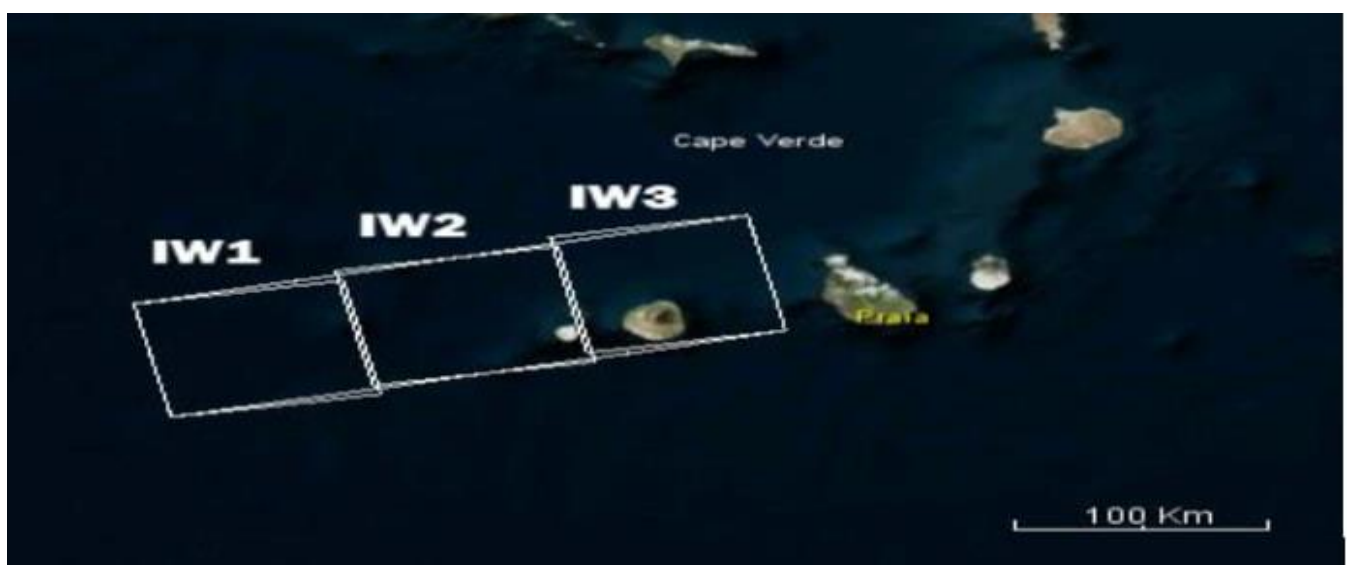

Figure 4. Sub-swaths IW1, IW2, IW3 of the study area (Luis, 2015)

\section{Co-registration and enhanced spectral diversity}

One of the main basic steps of InSAR processing is accurate co-registration of the slave and master images, by which the slave image is then resampled to match the 
geometry of the master image. Co-registration process is done by using the coherence between the two satellite imageries (Kervyn, 2001). Once the imageries have been successfully stacked, it is then the co-registered image should be spectrally enhanced.

\section{Interferogram formation}

The interferogram is formed by using cross multiplication of each pixel in the two images (Kervyn, 2001; Nobile et al., 2018). An interferogram will be measured by the calculation of phase differences $\left(\Delta \Phi_{\text {int }}\right)$ between the two co-registered SAR imageries (Schlögel et al., 2015; Eq. 1):

$$
\Delta \Phi_{\text {int }}=\Phi\left(t_{0}\right)-\Phi\left(t_{1}\right)=\Delta \Phi_{\text {def }}+\Delta \Phi_{\text {orb }}+\Delta \Phi_{\text {topo }}+\Delta \Phi_{\text {atm }}+\Delta \Phi_{\text {noise }}
$$

where $\Delta \Phi_{\text {int }}$ is interferometric phase, $\Phi\left(t_{0}\right)$ and $\Phi\left(t_{1}\right)$ are the phase values at day t0 and day $\mathrm{t} 1$, respectively. $\Delta \Phi_{\text {def }}$ is deformation between two acquisition times on ground, $\Delta \Phi_{\text {topo }}$ is topographic contribution, $\Delta \Phi_{\text {orb }}$ is orbital contribution, $\Delta \Phi_{\text {atm }}$ is atmospheric contribution and $\Delta \Phi_{\text {noise }}$ is noise contribution. In this step, the phase and the coherence bands (Figs. $5 A$ and $5 B$, respectively), were generated.

\section{Deburst}

TOPS data is acquired in bursts, which is separated by demarcation zones. However, any data within these zones can be considered invalid and must be debursted (Fig. 5C).

\section{Topographic phase removal and phase filter}

The created interferogram should be flattened using removing the topographic phase, by which the interferometric phase due to the curvature of the Earth is removed, however, to simulate the contribution of the topography to the interferometric phase a digital elevation model can be employed in conjunction with the baseline image, the topographic phase can then be removed from the interferogram (Kervyn, 2001). Because of the noisy nature of the created interferogram, a proper filter must be applied. There are a few common filters, which refer to Jebur et al. (2015) the best noise reduction is the Goldstein filter.

\section{Unwrapping}

The phase unwrapping associated with the integration of phase difference by adding the integer number of cycles, which minimises the phase difference (Kervyn, 2001). The range of the phase is represented in $2 \pi$ (Jebur et al., 2015). Once the time in phase reaches to $2 \pi$, the cycle will be repeated (Navarro-Sanchez et al., 2010). However, to address the $2 \pi$ ambiguity, phase unwrapping was employed using SNAPHU Software (Fig. 5D).

\section{Terrain correction}

Generally, terrain correction is the final step, by which the created InSAR will be geo-referenced and geometrically corrected. Terrain correction converts an image from either slant range or ground range geometry into a coordinate system (Kervyn, 2001). 

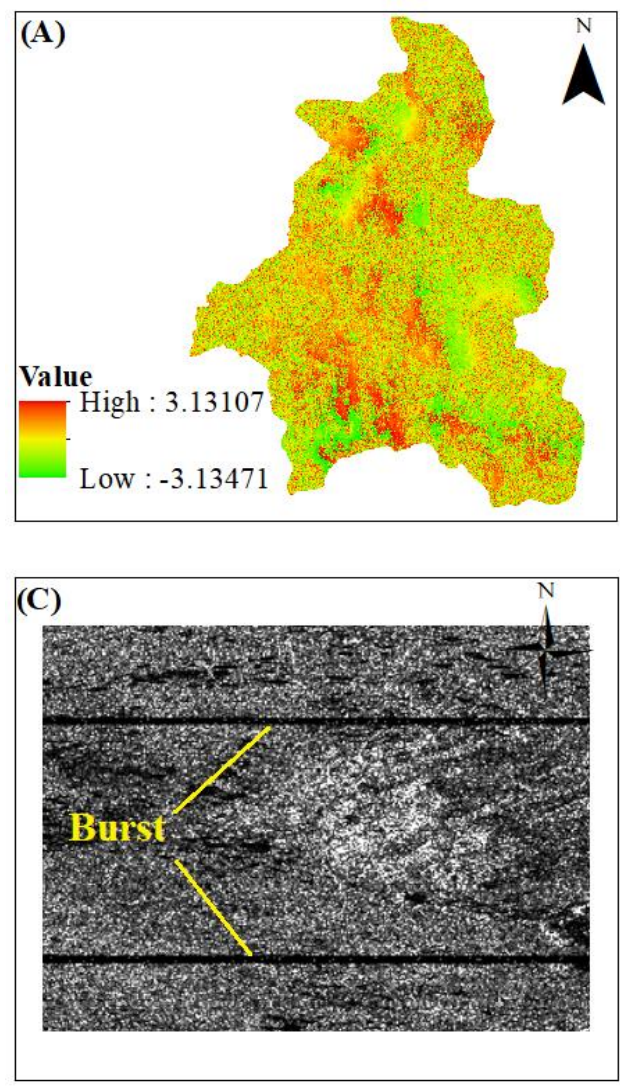
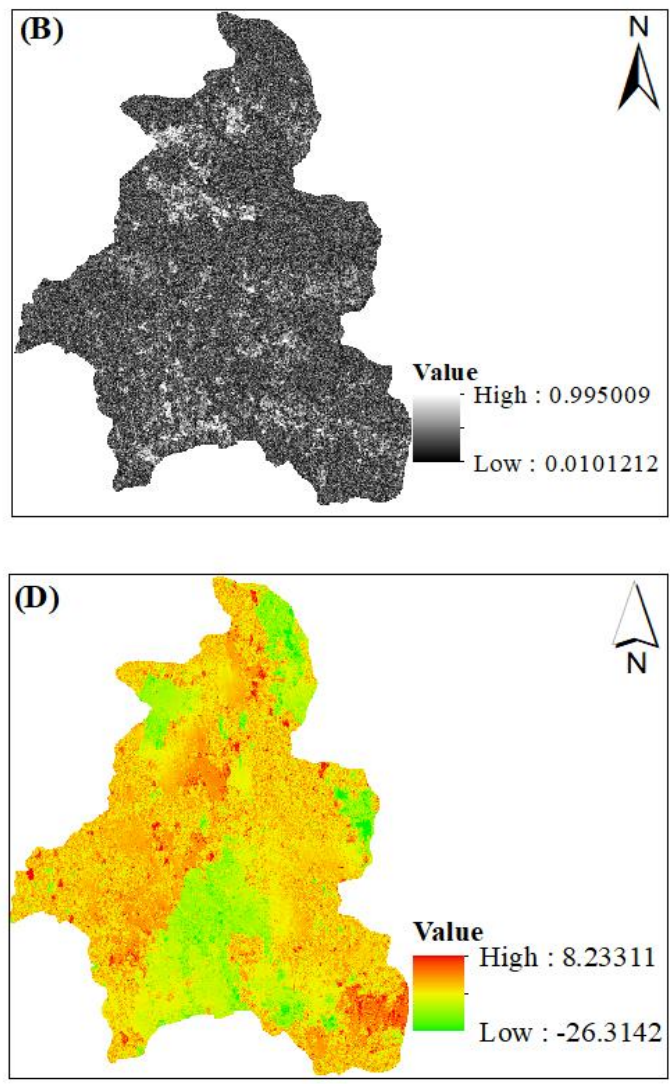

Figure 5. Interferogram formation process of applied data; (A) phase band, (B) coherence band, $(C)$ bursts in SENTINEL-1 imagery and $(D)$ unwrapped band

\section{The Google Earth and overlying the phase, coherence and unwrapped bands on it to detect landslide locations}

The Google Earth (GE) was originally developed in 2001 and its imageries displayed on a digital sphere retrieved from satellites or aircraft, which display the surface of the planet by a single composited image (Potere, 2008). However, after zooming, the imageries transitioned into finer details, which differ in time and date from one area to the next. Before Landsat-8 products, the imageries of Landsat-7 were used, which faced a hardware malfunction that resulted in spatial gaps in images (Markham et al., 2004). Now Landsat- 8 is used to provide imageries in a higher quality and frequency. However, resolution of the Google Earth imageries ranges from $15 \mathrm{~m}$ to $15 \mathrm{~cm}$ (Potere, 2008). The Google Earth is a valuable and free application that enables users to overly GIS data, satellite images and other maps from global to regional scales (Sönmez et al., 2011). The GE can be utilized to enhance cross discipline unification to support the national geography standards and education (Patterson, 2007).

In the current study, the phase, coherence and unwrapped bands of the generated InSAR map with the assist of the GE images were used to digitize landslide locations. Where, created phase, coherence and unwrapped bands were overlaid on the Google Earth. However, by zooming in and scrolling around in those areas in the abovementioned bands that there were a sign of land surface deformation the landslide locations were identified and digitized. 


\section{Validation}

Accuracy assessment points out the quality of obtained information (Alqurashi and Kumar, 2014). In this study, Geographical Positioning System (GPS) was used as a valuable tool for validating the extracted landslides. GPS is defined as one of the best techniques in deformation monitoring (Xiao and He, 2013). Because of its automated module and applicability in all-weather conditions, GPS by far is more helpful than the traditional geodetic survey (Leick et al., 2015). The spatial resolution of GPS depends highly on density of the antenna (Xiao and He, 2013). In the current study, 20\% of the detected landslides (30 locations out of 152 locations), were transferred into GPS to be validated in the region.

\section{Results and discussion}

\section{Landslide inventory}

Landslides are abrupt geomorphic events, which constitute the rapid downward motion of materials (Makoundi et al., 2014; Marchesini et al., 2018). The triggering mechanism for landslide in the study area is excessive precipitation, which downwards the natural stability of the slope, resulting in falling and sliding (Pradhan et al., 2010). Because of their stereo viewing capability and even high spatial resolution, RADAR satellite imageries have been extensively used to produce landslide inventory maps (Pradhan et al., 2016; Nobile et al., 2018).

Remote sensing technique is among helpful methods for identification of landslides (Singhroy et al., 1998; Guzzetti et al., 2012). Historical landslides for the study area were first recognized by the InSAR technique and then by overlying the phase, coherence and unwrapped bands on the Google Earth, the landslide locations were identified, digitized in either polygon or point layers. Using Geographical Information System (GIS), these layers were converted into shape-file format.

Figure 6 clearly shows the deformed surfaces in the phase, coherence and unwrapped bands. These bands were generated from SENTINEL-1 satellite imagery for two different dates (04/03/2016 and 20/02/2017), by using interferometry synthetic aperture RADAR (InSAR) technique and the SNAP software. In the phase and unwrapped bands (Figs. 6A and $C$ ), the deformed surfaces are shown in the red colour (The highest amount) and the green colour (The lowest amount). Furthermore, the coherence band is shown the deformed surfaces better than them, because white areas (High value), are clearly differentiated from stable places (Dark value) (Fig. 6B).

The phase, coherence and unwrapped bands of the generated InSAR map were converted into KML format and then were overlaid on the Google Earth. Wherever there was a sign of deformation by zooming in and scrolling around the landslide locations were detected and digitized. After zooming in the GE images, the imageries transitioned into the finer details. Which, deformed surfaces can be easily recognized, especially in vegetated areas, where landslide left bare lands. However, the study area of the current study is highly vegetated and completely appropriate for this kind of method (Fig. 7).

Table 2 and Figure 8 show the number of landslide inventory and their geographical position on the slope, aspect, and elevation maps, respectively. However, a total number of 129 landslides out of 152 landslides were occurred on the slope 11 to $40 \%$. Also based on the aspect map, the lowest and the highest number of the landslides were 
occurred on the flat and southeast classes of 0 and 32 landslides, respectively. Moreover, no landslide was found for elevation 1659 to $2067 \mathrm{~m}$ above the sea level, while 47 landslides were detected on the elevation class of 1,168 to $1,253 \mathrm{~m}$ above the sea level.

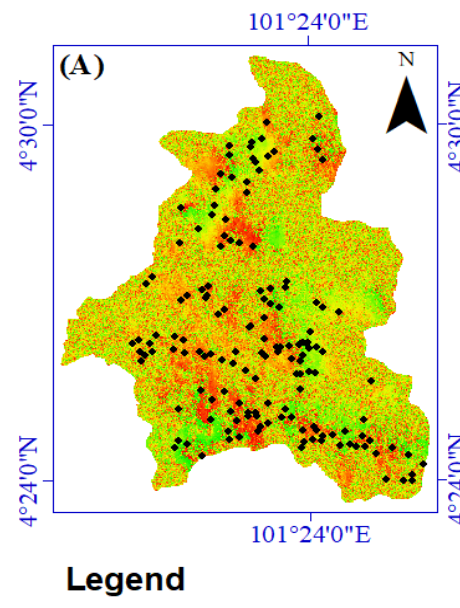

- Landslide locations

Phase band

Value

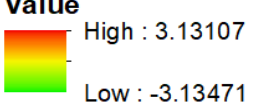

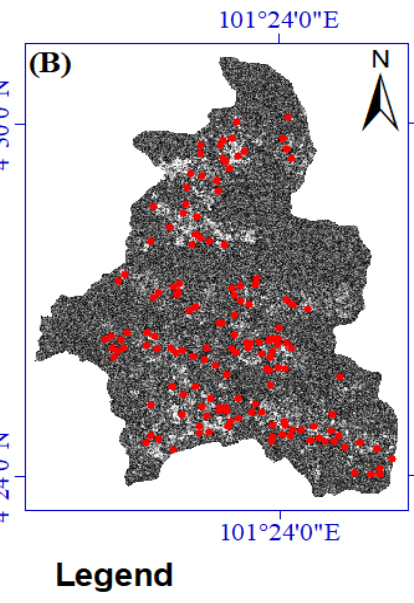

- Landslide locations Coherence band Value

- High : 0.995009

Low : 0.0101212

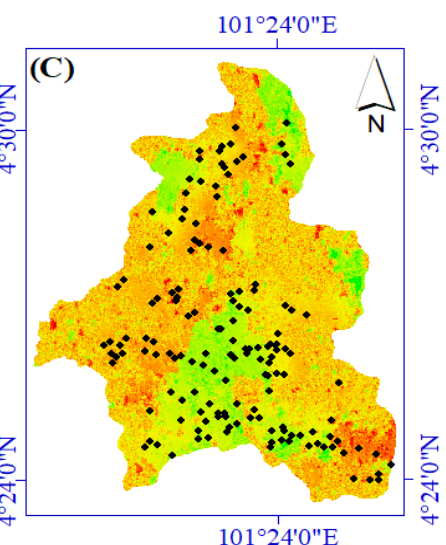

Legend

- Landslide locations

Unwrapped band

Value

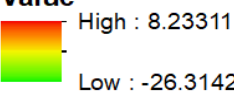

\begin{tabular}{|c|c|}
\hline & 13 Kilometers \\
\hline
\end{tabular}

Figure 6. The generated InSAR maps; (A) phase band, (B) coherence band, and (C) unwrapped band

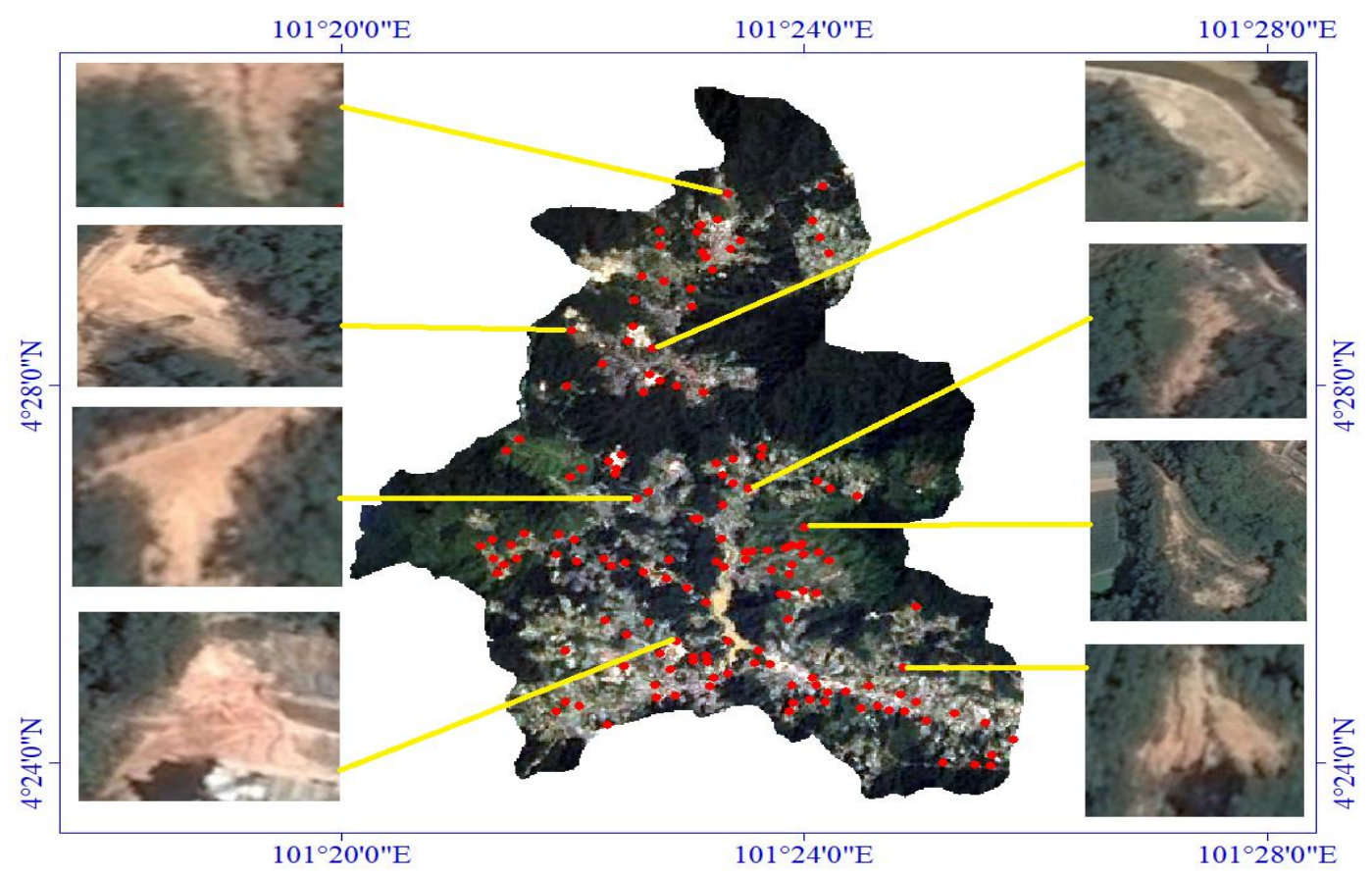

Figure 7. The importance of the Google Earth imagery in the produced landslide inventory 
Table 2. Number of occurred landslides on the slope, aspect, and elevation classes

\begin{tabular}{c|c|c|c|c|c}
\hline $\begin{array}{c}\text { Slope classes } \\
(\%)\end{array}$ & $\begin{array}{c}\text { No. occurred } \\
\text { landslide }\end{array}$ & Aspect classes & $\begin{array}{c}\text { No. occurred } \\
\text { landslide }\end{array}$ & $\begin{array}{c}\text { Elevation classes } \\
(\mathbf{M})\end{array}$ & $\begin{array}{c}\text { No. occurred } \\
\text { landslide }\end{array}$ \\
\hline $0-10$ & 11 & Flat & 0 & $920.1-1,077$ & 21 \\
\hline $11-20$ & 37 & North & 22 & $1,078-1,167$ & 27 \\
\hline $21-30$ & 57 & Northeast & 21 & $1,168-1,253$ & 47 \\
\hline $31-40$ & 35 & East & 23 & $1,254-1,338$ & 22 \\
\hline $41-50$ & 10 & Southeast & 32 & $1,339-1,424$ & 5 \\
\hline $51-60$ & 1 & South & 16 & $1,425-1,500$ & 11 \\
\hline $61-70$ & 0 & Southwest & 18 & $1,501-1,572$ & 16 \\
\hline $71-84$ & 1 & West & 5 & $1,573-1,658$ & 3 \\
\hline------ & - & Northwest & 15 & $1,659-1,770$ & 0 \\
\hline------ & - & --------- & - & $1,771-2,067$ & 0 \\
\hline
\end{tabular}

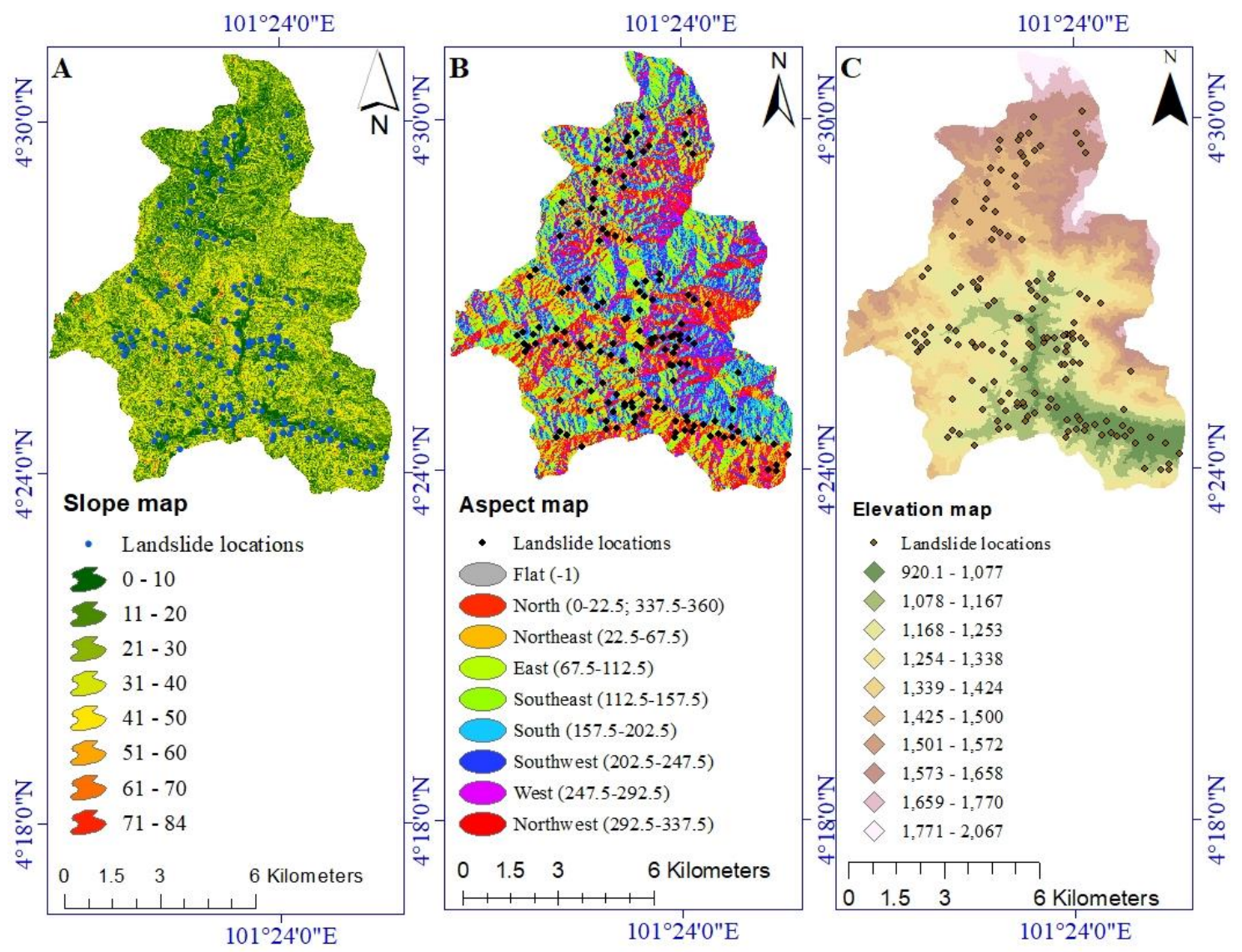

Figure 8. Occurred landslide locations; slope (A), aspect (B), and elevation (C) maps

The approach used in this study differs from previous inventory works in a number of ways:

- Convergence of satellite imagery, the Google Earth and extensive field survey 
- Applying field survey to check 20\% (30 landslide locations) of detected landslides despite limited field access

- Using SENTINEL-1 satellite imagery as the only RADAR imagery online for free

\section{Validation}

The Landslide locations were validated using GPS in the study area. However, 30 landslide locations (20\%) out of the total number of 152 locations were transmitted into GPS and validated in the study area. The field checks imply that the landslides were correctly mapped, therefore integration method used in the current research is applicable and valuable to detect landslide in a vegetated and cloudy region. Figure 9 indicates the geographical position of the validated landslides. However, for better understanding we have attached a few photos of the validated landslides in the figure. From the total number of 152 landslide locations, 64 landslides have an area larger than $500 \mathrm{~m}^{2}$ and the remaining 88 landslides have an area smaller than $500 \mathrm{~m}^{2}$. However, the smallest and the largest landslides have areas of $40 \mathrm{~m}^{2}$ and $5735 \mathrm{~m}^{2}$, respectively.

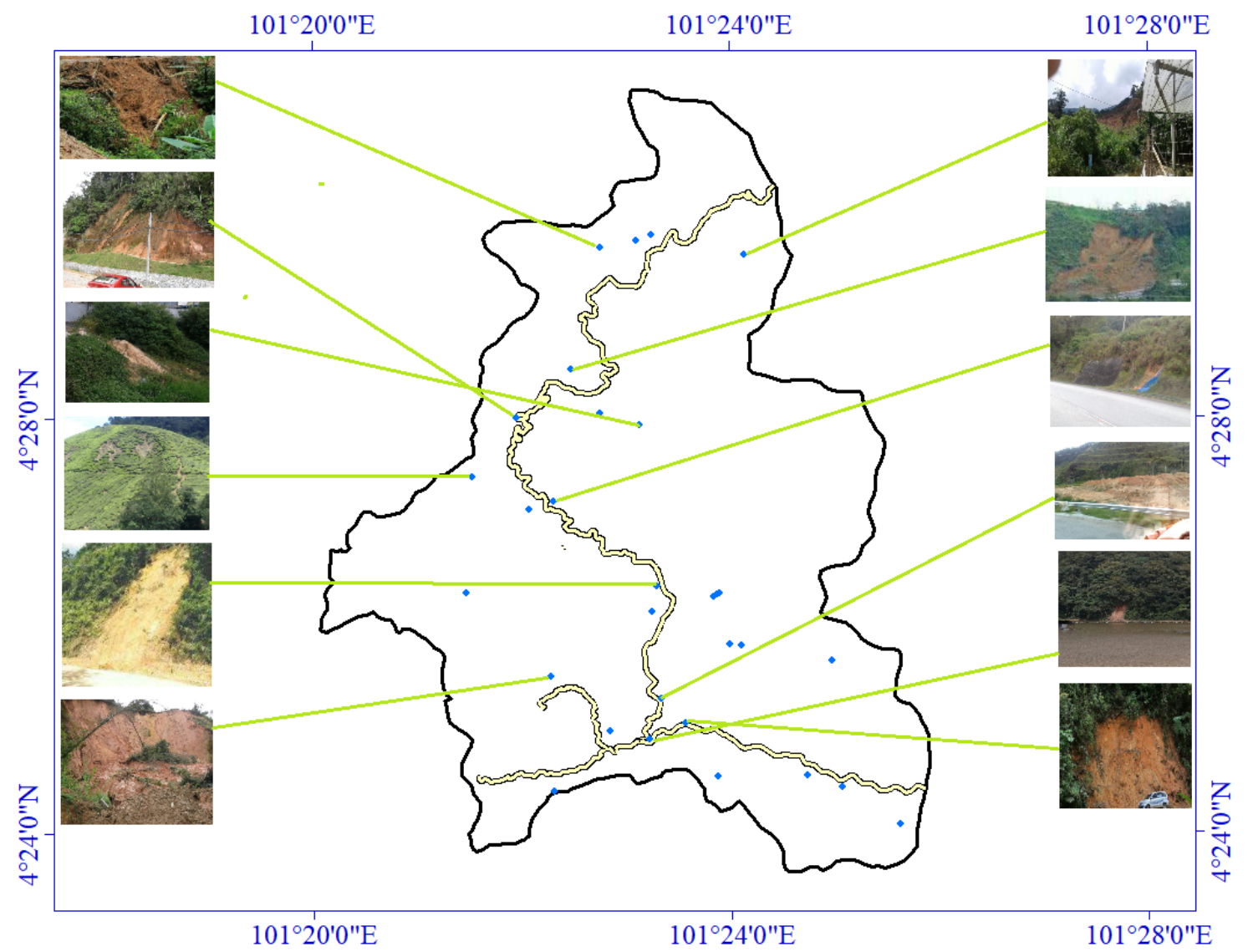

Figure 9. Shows the validated landslide locations using GPS

Table 3 lists the area and attributes of landslide locations, which were used for validation purposes in this study. These locations were randomly selected for field checks, however, the biggest and the smallest landslides have the areas of $2625 \mathrm{~m}^{2}$ and $78 \mathrm{~m}^{2}$, respectively. 
Table 3. Lists the validated landslide locations in the study area using GPS

\begin{tabular}{c|c|c|c}
\hline No. & Area_m $\mathbf{m}^{\mathbf{2}}$ & X coordinate & Y coordinates \\
\hline 1 & 332 & 761669.703 & 491002.116 \\
2 & 232 & 763152.498 & 489538.965 \\
3 & 365 & 763213.396 & 487495.887 \\
4 & 135 & 761762.287 & 493068.394 \\
5 & 930 & 763183.593 & 492653.848 \\
6 & 601 & 762771.802 & 492493.392 \\
7 & 1278 & 766107.429 & 487775.765 \\
8 & 369 & 767715.562 & 487797.997 \\
9 & 2625 & 769429.086 & 486872.411 \\
10 & 163 & 768311.418 & 487589.843 \\
11 & 450 & 764924.011 & 497368.124 \\
12 & 101 & 764018.098 & 497145.497 \\
13 & 78 & 766583.302 & 497033.463 \\
14 & 270 & 764710.241 & 494005.554 \\
15 & 1157 & 764023.307 & 494201.886 \\
16 & 343 & 764662.954 & 497256.227 \\
17 & 323 & 763499.397 & 494990.104 \\
18 & 506 & 764943.555 & 490694.459 \\
19 & 229 & 766132.101 & 491018.098 \\
20 & 287 & 766095.916 & 490985.837 \\
21 & 454 & 762522.67 & 494101.393 \\
22 & 135 & 766032.607 & 490970.753 \\
23 & 1012 & 764210.016 & 488554.45 \\
24 & 626 & 764897.98 & 488425.154 \\
25 & 240 & 765555.957 & 488728.318 \\
26 & 490 & 765022.494 & 491144.831 \\
27 & 1744 & 766337.317 & 490121.71 \\
28 & 1044 & 766529.743 & 489822.915 \\
29 & 523 & 768156.935 & \\
30 & 630 & 765132.229 & \\
\hline & & & \\
\hline
\end{tabular}

\section{Conclusion and recommendation}

Cameron Highlands are among the most landslide prone areas across Peninsular Malaysia. This work represents the integration of interferometry synthetic aperture RADAR (InSAR) technique with assist of the Google Earth image to identify the surface deformation of large and small landslides in a part of Cameron Highlands, Pahang, Malaysia. A pair of C-band SENTINEL-1 imagery were acquired, preprocessed, and then phase, coherence and unwrapped bands were generated to recognize the surface deformation. In order to address some limitations of interferometry synthetic aperture RADAR processing in mountainous terrains, different contributions to the interferometric phase are required. The topography phase must be removed, and then spectral filtering should be applied on the created interferogram. Generated phase band is wrapped, however using the SNAPHU software was unwrapped. 
By overlying the phase, coherence and unwrapped bands on the Google Earth the landslide locations were identified and digitized in both polygon and point layers. A total number of 152 landslides were identified. GPS was used to validate $20 \%$ of the total extracted landslide locations in the study area. SENTINEL-1 imagery with the ability of penetrating through cloud coverage and the applicability of getting data day and night in the cloudy regions like Cameron Highlands with assist of the Google Earth imagery supported by extensive field survey is a robust way for landslide inventory in the vegetated areas. Hence, the information provided by landslide inventory in the current study can be used for planners and engineers to make better decisions about landslide prevention, mitigation and avoidance through suitable prophylactic assessments and minimization procedures. We recommend more works for future researches to produce more detailed inventory map of occurred landslides in tropical environment like Cameron Highlands using L-band satellite imageries such us ALOSPALSAR-2 with $24 \mathrm{~cm}$ wavelength, which is able to penetrate further into vegetation coverage rather than C-band imageries like SENTINEL-1 satellite image, in order to more accurate detection of occurred landslides in the same study area situation.

Acknowledgements. We express our thanks to Editor-in-Chief of applied ecology and environmental research journal and our anonymous reviewers. With their comments and suggestions, we were able to significantly improve the quality of our paper. Also, authors wish to express their sincere thanks to Universiti Teknologi Malaysia (UTM) based on Research University Grant (Q.J130000.2527.17H84) for their financial supports.

\section{REFERENCES}

[1] Alqurashi, A. F., Kumar, L. (2014): Land use and land cover change detection in the Saudi Arabian desert cities of Makkah and Al-Taif using satellite data. - Advances in Remote Sensing 3: 106.

[2] Ardizzone, F., Fiorucci, F., Santangelo, M., Cardinali, M., Mondini, A. C., Rossi, M., Reichenbach, P., Guzzetti, F. (2013): Very-High Resolution Stereoscopic Satellite Images for Landslide Mapping. - In: Margottini, C. et al. (eds.) Landslide Science and Practice. Springer, Berlin.

[3] Bayer, B., Simoni, A., Mulas, M., Corsini, A., Schmidt, D. (2018): Deformation responses of slow moving landslides to seasonal rainfall in the Northern Apennines, measured by InSAR. - Geomorphology 308: 293-306.

[4] Bellotti, F., Bianchi, M., Colombo, D., Ferretti, A., Tamburini, A. (2014): Advanced InSAR Techniques to Support Landslide Monitoring. Mathematics of Planet Earth. Springer, Berlin.

[5] Brardinoni, F., Slaymaker, O., Hassan, M. A. (2003): Landslide inventory in a rugged forested watershed: a comparison between air-photo and field survey data. Geomorphology 54: 179-196.

[6] Broeckx, J., Vanmaercke, M., Duchateau, R., Poesen, J. (2018): A data-based landslide susceptibility map of Africa. - Earth-Science Reviews 185: 102-121.

[7] Bürgmann, R., Rosen, P. A., Fielding, E. J. (2000): Synthetic aperture radar interferometry to measure Earth's surface topography and its deformation. - Annual Review of Earth and Planetary Sciences 28: 169-209.

[8] Calvello, M., Peduto, D., Arena, L. (2017): Combined use of statistical and DInSAR data analyses to define the state of activity of slow-moving landslides. - Landslides 14: 473489. 
[9] Cascini, L., Fornaro, G., Peduto, D. (2010): Advanced low-and full-resolution DInSAR map generation for slow-moving landslide analysis at different scales. - Engineering Geology 112: 29-42.

[10] Chen, W., Peng, J., Hong, H., Shahabi, H., Pradhan, B., Liu, J., Zhu, A.-X., Pei, X., Duan, Z. (2018): Landslide susceptibility modelling using GIS-based machine learning techniques for Chongren County, Jiangxi Province, China. - Science of the Total Environment 626: 1121-1135.

[11] Chitroub, S., Houacine, A., Sansal, B. (2002): Statistical characterisation and modelling of SAR images. - Signal Processing 82: 69-92.

[12] Conoscenti, C., Rotigliano, E., Cama, M., Caraballo-Arias, N. A., Lombardo, L., Agnesi, V. (2016): Exploring the effect of absence selection on landslide susceptibility models: a case study in Sicily, Italy. - Geomorphology 261: 222-235.

[13] Costanzo, D., Cappadonia, C., Conoscenti, C., Rotigliano, E. (2012): Exporting a Google Earth $^{\mathrm{TM}}$ aided earth-flow susceptibility model: a test in central Sicily. - Natural Hazards 61: 103-114.

[14] Ferlisi, S., Peduto, D., Gullà, G., Nicodemo, G., Borrelli, L., Fornaro, G. (2015): The use of DInSAR Data for The Analysis of Building Damage Induced by Slow-Moving Landslides.- In: Lollino, G. et al. (eds.) Engineering Geology for Society and TerritoryVolume 2. Springer International, Switzerland.

[15] Fiorucci, F., Cardinali, M., Carlà, R., Rossi, M., Mondini, A., Santurri, L., Ardizzone, F., Guzzetti, F. (2011): Seasonal landslide mapping and estimation of landslide mobilization rates using aerial and satellite images. - Geomorphology 129: 59-70.

[16] García-Davalillo, J. C., Herrera, G., Notti, D., Strozzi, T., Álvarez-Fernández, I. (2014): DInSAR analysis of ALOS PALSAR images for the assessment of very slow landslides: the Tena Valley case study. - Landslides 11: 225-246.

[17] Garcia-Urquia, E., Yamagishi, H. (2017): Landslide Susceptibility Mapping Based on Aerial Photograph Interpretation Inventory for Tegucigalpa, Honduras: An Application of the Matrix Method. In: Yamagishi, H. Bhandary, N. P. (eds.) GIS Landslide. Springer, Japan.

[18] Geudtner, D., Torres, R., Snoeij, P., Davidson, M., Rommen, B. (2014): Sentinel-1 system capabilities and applications. - Geoscience and Remote Sensing Symposium (IGARSS), 2014 IEEE International, IEEE, pp. 1457-1460.

[19] Goldstein, R. M., Engelhardt, H., Kamb, B., Frolich, R. M. (1993): Satellite radar interferometry for monitoring ice sheet motion: application to an Antarctic ice stream. Science 262: 1525-1530.

[20] Greif, V., Vlcko, J. (2012): Monitoring of post-failure landslide deformation by the PSInSAR technique at Lubietova in Central Slovakia. - Environmental Earth Sciences 66: 1585-1595.

[21] Guzzetti, F., Mondini, A. C., Cardinali, M., Fiorucci, F., Santangelo, M., Chang, K.-T. (2012): Landslide inventory maps: New tools for an old problem. - Earth-Science Reviews 112: 42-66.

[22] Hanssen, R. F. (2001): Radar Interferometry: Data Interpretation and Error Analysis. Springer Science, Business Media, Dordrecht.

[23] Herrera, G., Gutiérrez, F., García-Davalillo, J., Guerrero, J., Notti, D., Galve, J., Fernández-Merodo, J., Cooksley, G. (2013): Multi-sensor advanced DInSAR monitoring of very slow landslides: the Tena Valley case study (Central Spanish Pyrenees). - Remote Sensing of Environment 128: 31-43.

[24] Herrera, G., Tomás, R., LÓPEZ-Sánchez, J. M., Delgado, J., Mallorqui, J., Duque, S., Mulas, J. (2007): Advanced DInSAR analysis on mining areas: La Union case study (Murcia, SE Spain). - Engineering Geology 90: 148-159.

[25] Infante, D., Confuorto, P., DI Martire, D., Ramondini, M., Calcaterra, D. (2016): Use of DInSAR data for multi-level vulnerability assessment of urban settings affected by slowmoving and intermittent landslides. - Procedia Engineering 158: 470-475. 
[26] Jebur, M. N., Pradhan, B., Tehrany, M. S. (2015): Using ALOS PALSAR derived highresolution DInSAR to detect slow-moving landslides in tropical forest: Cameron Highlands, Malaysia. - Geomatics \& Natural Hazards and Risk 6: 741-759.

[27] Kervyn, F. (2001): Modelling topography with SAR interferometry: illustrations of a favourable and less favourable environment. - Computers \& Geosciences 27: 1039-1050.

[28] Leick, A., Rapoport, L., Tatarnikov, D. (2015): GPS Satellite Surveying. - John Wiley \& Sons, Hoboken, NJ.

[29] Li, H. R., Pei, X., Zhang, X. (2015): Historical Co-seismic Landslides Inventory and Analysis Using Google Earth: A Case Study of 1920 M8. 5 Haiyuan Earthquake, China. - In: Lollino, G. et al. (eds.) Engineering Geology for Society and Territory-Volume 2. Springer International, Switzerland.

[30] Li, Z., Shi, W., Myint, S. W., Lu, P., Wang, Q. (2016): Semi-automated landslide inventory mapping from bitemporal aerial photographs using change detection and level set method. - Remote Sensing of Environment 175: 215-230.

[31] Lillesand, T., Kiefer, R. W., Chipman, J. (2014): Remote Sensing and Image Interpretation. - John Wiley \& Sons, New York.

[32] Luis, V. (2015): TOPS Interferometry Tutorial. - Sentinel-1 Toolbox, issued in May.

[33] Maki Mateso, J.-C., Monsieurs, E., Jacobs, L., Bagalwa Mateso, L., Fiama Bondo, S., Delvaux, D., Albino, F., Kervyn, F., Dewitte, O. (2016): A regional inventory of the landslide processes and the elements at risk on the Rift flanks west of Lake Kivu (DRC). - EGU General Assembly Conference Abstracts 6345.

[34] Makoundi, C., Zaw, K., Large, R. R., Meffre, S., Lai, C.-K., Hoe, T. G. (2014): Geology, geochemistry and metallogenesis of the Selinsing gold deposit, central Malaysia. Gondwana Research 26: 241-261.

[35] Marcelino, E. V., Formaggio, A. R., Maeda, E. E. (2009): Landslide inventory using image fusion techniques in Brazil. - International Journal of Applied Earth Observation and Geoinformation 11: 181-191.

[36] Marchesini, I., Santangelo, M., Fiorucci, F., Cardinali, M., Rossi, M., Bucci, F., Guzzetti, F. (2018): TXT-tool 1.039-1.2 Bedding Attitude Information Through the Interpretation of Stereoscopic Aerial Photographs and GIS Modeling. - In: Sassa, K. et al. (eds.) Landslide Dynamics: ISDR-ICL Landslide Interactive Teaching Tools. - Springer International, Switzerland.

[37] Markham, B. L., Storey, J. C., Williams, D. L., Irons, J. R. (2004): Landsat sensor performance: history and current status. - IEEE Transactions on Geoscience and Remote Sensing 42: 2691-2694.

[38] Massonnet, D., Feigl, K. L. (1998): Radar interferometry and its application to changes in the Earth's surface. - Reviews of Geophysics 36: 441-500.

[39] Massonnet, D., Rossi, M., Carmona, C., Adragna, F., Peltzer, G., Feigl, K., Rabaute, T. (1993): The displacement field of the Landers earthquake mapped by radar interferometry. - Nature 364: 138.

[40] Motagh, M., Wetzel, H.-U., Roessner, S., Kaufmann, H. (2013): A TerraSAR-X InSAR study of landslides in southern Kyrgyzstan, central Asia. - Remote Sensing Letters 4: 657-666.

[41] Navarro-Sanchez, V. D., Lopez-Sanchez, J. M., Vicente-Guijalba, F. (2010): A contribution of polarimetry to satellite differential SAR interferometry: Increasing the number of pixel candidates. - IEEE Geoscience and Remote Sensing Letters 7: 276-280.

[42] Nichol, J., Wong, M. (2005): Satellite remote sensing for detailed landslide inventories using change detection and image fusion. - International Journal of Remote Sensing 26: 1913-1926.

[43] Nichol, J. E., Shaker, A., Wong, M.-S. (2006): Application of high-resolution stereo satellite images to detailed landslide hazard assessment. - Geomorphology 76: 68-75.

[44] Nobile, A., Dille, A., Monsieurs, E., Basimike, J., Bibentyo, T. M., D’oreye, N., Kervyn, F., Dewitte, O. (2018): Multi-Temporal DInSAR to Characterise Landslide Ground 
Deformations in a Tropical Urban Environment: Focus on Bukavu (DR Congo). Remote Sensing 10: 626.

[45] Patterson, T. C. (2007): Google Earth as a (not just) geography education tool. - Journal of Geography 106: 145-152.

[46] Pauciullo, A., Esposito, C., Jackson, G., Lanari, R., Perna, S. (2015): Maximum Likelihood approach for the phase offset estimation in InSAR DEM generation. Geoscience and Remote Sensing Symposium (IGARSS), 2015 IEEE International, IEEE, pp. 3838-3841.

[47] Pham, B. T., Bui, D., Prakash, I., Dholakia, M. (2016): Evaluation of predictive ability of support vector machines and naive Bayes trees methods for spatial prediction of landslides in Uttarakhand state (India) using GIS. - J Geomatics 10: 71-79.

[48] Pham, B. T., Bui, D. T., Pourghasemi, H. R., Indra, P., Dholakia, M. (2017): Landslide susceptibility assesssment in the Uttarakhand area (India) using GIS: a comparison study of prediction capability of naïve bayes, multilayer perceptron neural networks, and functional trees methods. - Theoretical and Applied Climatology 128: 255-273.

[49] Potere, D. (2008): Horizontal positional accuracy of Google Earth's high-resolution imagery archive. - Sensors 8: 7973-7981.

[50] Potin, P., Bargellini, P., Laur, H., Rosich, B., Schmuck, S. (2012): Sentinel-1 mission operations concept. - Geoscience and Remote Sensing Symposium (IGARSS), 2012 IEEE International, IEEE, pp. 1745-1748.

[51] Pradhan, B., Sezer, E. A., Gokceoglu, C., Buchroithner, M. F. (2010): Landslide susceptibility mapping by neuro-fuzzy approach in a landslide-prone area (Cameron Highlands, Malaysia). - IEEE Transactions on Geoscience and Remote Sensing 48: 4164-4177.

[52] Pradhan, B., Jebur, M. N., Shafri, H. Z. M., Tehrany, M. S. (2016): Data fusion technique using wavelet transform and Taguchi methods for automatic landslide detection from airborne laser scanning data and quickbird satellite imagery. - IEEE Transactions on Geoscience and Remote Sensing 54: 1610-1622.

[53] Rasul, M., Islam, M. S., Yunus, R. B. M., Mokhtar, M. B., Alam, L., Yahaya, F. (2017): Spatial and Temporal Variation of Water Quality in the Bertam Catchment, Cameron Highlands, Malaysia. - Water Environment Research 89: 2088-2102.

[54] Schlögel, R., Doubre, C., Malet, J.-P., Masson, F. (2015): Landslide deformation monitoring with ALOS/PALSAR imagery: a D-InSAR geomorphological interpretation method. - Geomorphology 231: 314-330.

[55] Shahabi, A. B., Khezri, S. (2013): Evaluation and comparison of bivariate and multivariate statistical methods for landslide susceptibility mapping (case study: Zab basin). - Arabian Journal of Geosciences 6: 3885-3907.

[56] Shahabi, H. M. (2015): Landslide susceptibility mapping using GIS-based statistical models and Remote sensing data in tropical environment. - Scientific reports 5: 9899.

[57] Shahabi, H., M., Ahmad, B. B. (2015): Remote sensing and GIS-based landslide susceptibility mapping using frequency ratio, logistic regression, and fuzzy logic methods at the central Zab basin, Iran. - Environmental Earth Sciences 73: 8647-8668.

[58] Shahabi, K. S., Ahmad, B. B., Hashim, M. (2014): Landslide susceptibility mapping at central Zab basin, Iran: a comparison between analytical hierarchy process, frequency ratio and logistic regression models. - Catena 115: 55-70.

[59] Singh, L. P., van Westen, C., Ray, P. C., Pasquali, P. (2005): Accuracy assessment of InSAR derived input maps for landslide susceptibility analysis: a case study from the Swiss Alps. - Landslides 2: 221-228.

[60] Singhroy, V., Mattar, K., Gray, A. (1998): Landslide characterisation in Canada using interferometric SAR and combined SAR and TM images. - Advances in Space Research 21: 465-476. 
[61] Sönmez, İ., Erdi, E., Tekeli, A. E., Demir, F., Arslan, M. (2011): Foogle: fire monitoring tool for EUMETSAT's active fire product over Turkey using Google Earth. - Geomatics \& Natural Hazards and Risk 2: 1-13.

[62] Stevens, N., Wadge, G. (2004): Towards operational repeat-pass SAR interferometry at active volcanoes. - Natural Hazards 33: 47-76.

[63] Strozzi, T., Ambrosi, C., Raetzo, H. (2013): Interpretation of aerial photographs and satellite SAR interferometry for the inventory of landslides. - Remote Sensing 5: 25542570.

[64] Sun, Q., Zhang, L., Ding, X., Hu, J., Li, Z., Zhu, J. (2015): Slope deformation prior to Zhouqu, China landslide from InSAR time series analysis. - Remote Sensing of Environment 156: 45-57.

[65] Tang, Y., Zhang, Z., Wang, C., Zhang, H., Wu, F., Liu, M. (2015): Characterization of the giant landslide at Wenjiagou by the insar technique using TSX-TDX CoSSC data. Landslides 12: 1015-1021.

[66] Tien Bui, D., Shahabi, H., Shirzadi, A., Chapi, K., Alizadeh, M., Chen, W., Mohammadi, A., Ahmad, B., Panahi, M., Hong, H., Tian, Y. (2018): Landslide detection and susceptibility mapping by AIRSAR data using support vector machine and index of entropy models in Cameron Highlands, Malaysia. - Remote Sensing 10: 1527-1542.

[67] Tomás, R., Márquez, Y., Lopez-Sanchez, J. M., Delgado, J., Blanco, P., Mallorquí, J. J., Martínez, M., Herrera, G., Mulas, J. (2005): Mapping ground subsidence induced by aquifer overexploitation using advanced Differential SAR Interferometry: Vega Media of the Segura River (SE Spain) case study. - Remote Sensing of Environment 98: 269-283.

[68] Tomás, R., Romero, R., Mulas, J., Marturià, J. J., Mallorquí, J. J., Lopez-Sanchez, J. M., Herrera, G., Gutiérrez, F., González, P. J., Fernández, J. (2014): Radar interferometry techniques for the study of ground subsidence phenomena: a review of practical issues through cases in Spain. - Environmental Earth Sciences 71: 163-181.

[69] Tomás, R., Li, Z., Lopez-Sanchez, J. M., Liu, P., Singleton, A. (2016): Using wavelet tools to analyse seasonal variations from InSAR time-series data: a case study of the Huangtupo landslide. - Landslides 13: 437-450.

[70] Van Baelen, J., Richmond, A. (1991): Radar interferometry technique: Three-dimensional wind measurement theory. - Radio Science 26: 1209-1218.

[71] Van den Eeckhaut, M., Hervás, J., Jaedicke, C., Malet, J.-P., Montanarella, L., Nadim, F. (2012): Statistical modelling of Europe-wide landslide susceptibility using limited landslide inventory data. - Landslides 9: 357-369.

[72] Wang, S., Yang, B., Zhou, Y., Wang, F., Zhang, R., Zhao, Q. (2018): Three-dimensional information extraction from GaoFen-1 satellite images for landslide monitoring. Geomorphology 309: 77-85.

[73] Wieczorek, G. F. (1984): Preparing a detailed landslide-inventory map for hazard evaluation and reduction. - Bulletin of the Association of Engineering Geologists 21: 337-342.

[74] Wright, T. J., Ebinger, C., Biggs, J., Ayele, A., Yirgu, G., Keir, D., Stork, A. (2006): Magma-maintained rift segmentation at continental rupture in the 2005 Afar dyking episode. - Nature 442: 291.

[75] Xiao, R., He, X. (2013): Real-time landslide monitoring of Pubugou hydropower resettlement zone using continuous GPS. - Natural Hazards 69: 1647-1660.

[76] Yamagishi, H., Moncada, R. (2018): TXT-tool 1.081-3.1 Landslide Recognition and Mapping Using Aerial Photographs and Google Earth. - In: Sassa, K. et al. (eds.) Landslide Dynamics: ISDR-ICL Landslide Interactive Teaching Tools. - Springer International, Switzerland.

[77] Yang, X., Chen, L. (2010): Using multi-temporal remote sensor imagery to detect earthquake-triggered landslides. - International Journal of Applied Earth Observation and Geoinformation 12: 487-495. 